\title{
AS INFLUÊNCIAS SOCIAIS NA CONSTRUÇÃO DA IDENTIDADE DE GÊNERO
}

\author{
Danielly de Sousa Bezerra ${ }^{1}$, Universidade Federal de Campina Grande (UFCG) \\ E-mail:danibiologia20@gmail.com \\ Danilly de Sousa Bezerra², Universidade Federal de Campina Grande (UFCG) \\ E-mail: danillygirl@gmail.com \\ Jefferson Antonio Marques ${ }^{3}$,Universidade Federal de Campina Grande (UFCG) \\ E-mail: jeffymarques@gmail.com
}

\begin{abstract}
RESUMO
O estudo proposto tem como objetivo investigativo observar alguns fatores que podem influenciar na identidade de gênero das crianças, o papel da escola nessa construção, as influências sociais e como os pais podem influir para reforçar os estereótipos. O trabalho trata-se de uma pesquisa bibliográfica, de natureza básica e de caráter qualitativo realizada por alunas do Centro de Formação de Professores da Universidade Federal de Campina Grande - CFP/UFCG, que perceberam a necessidade de um olhar mais atento à temática. Os resultados apontam que o recém-nascido nasce com o sexo e desenvolve a preferência de identidade mais tarde. Dessa forma, essas diferenças não são estabelecidas biologicamente - são culturalmente formadas. É preciso estimular que as crianças se divirtam juntas, sem fazer distinção entre elas, sem impor que brinquem com brinquedos e atividades separadas pelo gênero. A escola pode atuar nessa socialização de gênero devido ao longo tempo que as crianças passam nesse ambiente; por isso, discutir gênero nas escolas é importante e urgente, afinal, o papel do ambiente escolar não é somente preparar os alunos para provas e vestibulares, mas também promover a cidadania e a responsabilidade social para professores, coordenadores, funcionários, alunos e suas famílias.
\end{abstract}

PALAVRAS-CHAVE: Gênero; Identidade; Escola.

\begin{abstract}
The proposed study aims to investigate some factors that may influence the gender identity of the children, the role of the school in this construction, how social influences and how parents can influence to reinforce the stereotypes. This paper is a bibliographical research, basic and qualitative character conducted by students of the Teacher Training Center of the Federal University of Campina Grande CFP/UFCG who realized the need for a closer look at the subject. The results indicate that the newborn is born with sex and develops the identity preference later. In this way, these differences are not established biologically - they are culturally formed. It is necessary to encourage children to have fun together, without distinction between them, without requiring them to play with toys and activities separated by gender. The school can act in this gender socialization because of the long time that children
\end{abstract}

Revista de Pesquisa Interdisciplinar, Cajazeiras, n. 2, suplementar, p. 29 - p. 37, set. de 2017. 
spend in this environment. Therefore, discussing gender in school is important and urgent; after all, the role of the school environment is not only to prepare students for tests and exams, but also to promote citizenship and social responsibility for teachers, coordinators, staff, students and their families.

KEYWORDS: Genre; Identity; School.

\section{INTRODUÇÃO}

Frequentemente se associa a questão de gênero com o sexo biologicamente definido; no entanto, a natureza do ser homem ou mulher não pode ser facilmente classificada. Para discussões sobre gênero é preciso, primeiramente, saber diferenciar esses dois termos. Sexo é um termo com certa ambiguidade, uma vez que pode relacionar-se à atividade sexual; contudo, a palavra faz referência também às diferenças anatômicas e fisiológicas que definem os corpos masculinos e femininos. Já gênero está ligado às noções de masculinidade e feminilidade, não sendo necessariamente produto direto do sexo biológico do indivíduo - ora um indivíduo nasce com o sexo biológico definido, por exemplo, do sexo masculino, mas pode se identificar como mulher.

Essa distinção é fundamental, pois a partir dela é possível compreender que muitas diferenças entre homens e mulheres não têm base biológica. Existem argumentos que defendem essas diferenças como de origem biológica e outros que afirmam que nem o gênero e nem o sexo tem origem na biologia, mas que são construções sociais. Segundo Jesus (2012, p.05),

Cada um (a) de nós é uma pessoa única que, porém, tem características comuns a toda a humanidade. Elas nos identificam com alguns e nos tornam diferentes de outros, como a região em que nascemos e crescemos, nossa raça, classe social, se temos ou não uma religião, idade, nossas habilidades físicas, entre outras que marcam a diversidade humana.

Assim, questiona-se até que ponto as diferenças no comportamento de mulheres e homens são resultados das diferenças biológicas. Alguns autores sustentam que determinados aspectos biológicos como hormônios, cromossomos e características de base genética, por exemplo, são responsáveis por diferenças inatas de comportamento entre ambos. Dessa forma sustentam que os fatores naturais são responsáveis pela desigualdade dos gêneros -

Revista de Pesquisa Interdisciplinar, Cajazeiras, n. 2, suplementar, p. 29 - p. 37, set. de 2017. 
característica da maioria das sociedades. No entanto, alguns pesquisadores não se convencem com esse argumento. Os críticos observam que as teorias da "diferença natural" se baseiam costumeiramente em comportamento "animalão" invés de se basearem no comportamento humano, isto é, nas evidências históricas e antropológicas sobre o comportamento que mostram que há variação no tempo e lugar. De acordo com Peretti e Natel (2013, p.171),

Em função das críticas e das tensões / transformações nas reivindicações dos movimentos feministas é que surge o gênero como categoria de análise histórica, convergindo com tendências historiográficas emergentes, entre elas a "história cultural". Sem dúvida, a categoria gênero reivindica para si um território específico, em face da insuficiência dos corpos teóricos existentes para explicar a persistência da desigualdade entre mulheres e homens.

A hipótese de que os fatores biológicos determinam os padrões de comportamento não pode ser rejeitada de um todo, embora nenhum estudo tenha tido sucesso em comprová-la. Essa hipótese, ao considerar que os indivíduos têm predisposição conata, negligencia o papel essencial da interação social em moldar o comportamento humano. De acordo com Jesus (2012, p. 05), crescemos sendo ensinados que "homens são assim e mulheres são assado, porque é da sua natureza, e costumamos realmente observar isso na sociedade".

As identidades dos gêneros podem suceder de influências sociais, os brinquedos na infância, os jogos na adolescência, nosso vestuário, os gestos e o palavreado que nos são ensinados e as relações estabelecidas com os grupos de pares e com as pessoas adultas vão nos informando sobre como é ser homem e mulher na sociedade e nos levam a distinguir quais atitudes são as mais apropriadas a cada gênero.

Os pais podem usar de maneiras sutis para reforçar os estereótipos de gênero. Por exemplo, normalmente são mais propícios a dar carrinhos de brinquedo, bonecos de ação e equipamentos esportivos aos meninos e bonecas, conjuntos de cozinha e brinquedos de vestir às suas filhas. Normalmente quando a criança é do sexo feminino, ornamenta-se o quarto com itens de cor rosa ou lilás; dos meninos, na cor azul ou verde. 
Em um estudo feito por Costa e Antoniazzi (1999), as autoras destacam que os pais têm bastante influência sobre o desenvolvimento do gênero dos seus filhos, onde ao fazerem essa distinção de brinquedos estereotipados para cada sexo acabam por intervir nessa identidade.

A escola também pode influenciá-los, tendo em vista que é o local onde as crianças e jovens passam a maior parte do tempo. Sendo assim, essa discussão de identidade de gênero deve ser trabalhada nesse ambiente, o qual deve servir como um subsidio de orientação e ajudar os alunos a se redescobrirem nessa construção de identificação. Nesse sentido, Carvalho (2012, p. 210) retrata que "se considerarmos que as identidades são modos de inscrição que vinculam as instituições e os seres ao meio e à cultura, a escola, querendo ou não, estará sempre presente no processo identitário dos adolescentes".

Nessa perspectiva, o presente trabalho trata-se de uma pesquisa com o objetivo de observar alguns fatores que podem influenciar na identidade de gênero das crianças, o papel da escola nessa construção, as influências sociais e como os pais podem influir para reforçar os estereótipos.

\section{METODOLOGIA}

A pesquisa foi realizada por alunas do Curso de Licenciatura em Ciências Biológicas e Letras- Língua Portuguesa, do Centro de Formação de Professores da Universidade Federal de Campina Grande-CFP/UFCG, em maio de 2017, com o intuito de analisar quais fatores podem influenciar na identidade de gênero, o papel dos pais e da escola nessa construção de identidade.

Em conformidade com Neves et al. (2013), quanto aos procedimentos a pesquisa é do tipo bibliográfica e de natureza básica, uma vez que foram discutidos dados já existentes. Tratase de uma pesquisa descritiva, tendo em vista que o assunto tratado já foi explorado por outros autores; e quanto à abordagem é qualitativa, pois esclarece o porquê das coisas, manifestando o que condiz ser feito.

Após a coleta, os dados foram analisados e discutidos, sendo comparados com trabalhos já publicados.

\section{RESULTADOS E DISCUSSÃO}


De acordo com a metodologia descrita, foram analisados alguns pontos relacionados ao objetivo da pesquisa.

A socialização dos gêneros mostra a diferenciação entre o sexo biológico e o gênero social. As crianças assimilam quais as expectativas sociais, atitudes e os comportamentos associados aos meninos e às meninas. O recém-nascido nasce com o sexo e desenvolve a preferência de identidade mais tarde. Dessa forma, essas diferenças não são estabelecidas biologicamente - são culturalmente formadas. Assim, acredita-se que isso ocorre pelo fato de homens e mulheres serem socializados para comportamentos distintos. Essas relações são estruturadas a partir de aspectos que integram a sociedade, tais como poder, trabalho e as relações pessoais e emotivas entre pessoas, permitindo o questionamento sobre as mudanças que estamos sofrendo diariamente, na medida em que estas são envolvidas pela nossa identidade e perspectiva de gênero, ajustando-se constantemente.

Hoje já podemos nos deparar com mulheres e homens nas mais variadas profissões, ultrapassando, assim, essas barreiras, onde mulheres trabalham na construção civil ou como motorista de ônibus van, caminhão; estão cada vez mais envolvidas na política, assim como também observamos homens em profissões que até então não era considerada apropriadas para eles como enfermeiros, cozinheiros, dançarinos, entre outras. De acordo com Cunha e Santos (2014, p. 01),

\footnotetext{
Vários estudos estão sendo feitos para debater e demonstrar ações que busquem a igualdade entre homens e mulheres poderão contribuir na construção de um mundo que seja plural, onde o feminino e o masculino não sejam oprimidos nem opressores, buscando assim desconstruir certas práticas, discursos e representações que discriminam, oprimem e submetem algumas pessoas em função do gênero.
}

O gênero é uma forma de estratificação social. Sabe-se que os papéis de homens e mulheres em diferentes sociedades mudam, mas não existe uma só sociedade na qual elas tenham mais poder ou exerçam maior influência que eles. Apesar do avanço que as mulheres fizeram em alguns países, as desigualdades de gênero continuam a servir como desigualdades sociais. 
Nas abordagens funcionalistas alguns autores sustentam a ideia das "diferenças naturais" entre o homem e mulher e da estrutura socialista onde a criança não pode ficar sem a presença da mãe e que essa mãe não possa ser substituída caso ela não possa estar presente, e se houver substituição a figura materna tem que ser feminina, muitos autores usam essa ideia, para oprimir as mulheres que trabalham afirmando que elas estão negligenciando seus filhos.

Evidencia-se que essa distinção entre homens e mulheres é formada a partir do convívio social, desde a infância as crianças são orientadas a se comportarem de acordo com o sexo, sendo que o gênero deve ser expressado da mesma forma, visto como apropriado pelos pais e a sociedade (JESUS, 2012).

A mídia também pode influenciar na identidade de gênero, uma vez que a exposição das crianças a esse meio pode afetar seus comportamentos verbais e não verbais. As crianças podem assistir filme, desenho ou vídeo e quererem ser como os personagens. Normalmente as crianças percebem padrões de gênero em atitudes e com comportamentos tidos como aceitáveis, e procuram adaptar-se a eles.

Outro ponto importante é a questão do gênero no ambiente escolar, onde, por muitas vezes, gestores e educadores não sabem lidar com a situação, pois para eles não é algo "normal”, ou seja, não está no padrão da sociedade. O que nota-se são as práticas pedagógicas cotidianas que podem estar permeadas por discursos e atitudes que revelam preconceitos de gênero. Por exemplo, para organizar a sala de aula e garantir uma boa disciplina, é comum a utilização de frases como "vocês estão parecendo mulherzinhas"; "isso é coisa de menino/de homem"; "Peça para as meninas limparem isso"; "Mande os meninos carregarem a caixa"; "As meninas estão muito saidinhas".

O processo de construção da identidade de gênero tem importância fundamental para o desenvolvimento dos indivíduos, pois determina interesses, atitudes e comportamentos que o acompanharão ao longo da vida. $\mathrm{O}$ ponto de maior interesse sobre este tema refere-se à maneira pela qual ocorre a formação do conceito de identidade de gênero, através da qual os indivíduos irão perceber a existência da diferença sexual, posteriormente identificando-se como homens ou mulheres (COSTA; ANTONIAZZI, 1999, p. 67). 
Conforme Ribeiro (2012), a escola deve se preocupar para não acrescentar o preconceito, educar seus alunos para que mesmo que não aceitem saibam respeitar essa pluralidade de diferenças, reprovando assim qualquer forma de discriminação com o próximo.

A escola, portanto, tem papel fundamental na construção da identidade dos indivíduos, inclusive nas sexuais e de gênero, por ser um espaço privilegiado para o afloramento e a proliferação dos temas ligados à sexualidade e às questões de gênero, e não somente entre os/as alunos/as, mas também entre os/as professores/as.

\section{CONCLUSÃO}

Durante a primeira infância, os pais podem tentar incentivar os filhos a brincar com uma variedade de brinquedos ou tarefas estereotipadas como masculinas e femininas. É preciso que seja deixado de lado, o pensamento de que apenas mulheres podem vestir da cor rosa, sendo que é uma cor como qualquer outra, onde qualquer pessoa pode fazer uso desta, independente do sexo. Enfim, os pais podem discutir e desafiar os estereótipos de gêneros com seus filhos.

É preciso estimular que as crianças se divirtam juntas, sem fazer distinção entre elas, sem impor que brinquem com brinquedos e atividades separadas pelo gênero; permitir que adolescentes transgêneros tenham um ambiente seguro onde sejam respeitados.

A escola pode atuar nessa socialização de gênero, devido ao longo tempo que as crianças passam nesse ambiente, a qual tem a responsabilidade de não contribuir para o aumento da discriminação e dos preconceitos contra as mulheres e contra todos aqueles que não correspondem a um ideal de masculinidade dominante, tendo em vista que alguns fatores podem influenciar na identidade de gênero, aprendizagem e formação de valores.

Para os alunos do ensino fundamental e médio pode-se introduzir esses temas por meio de análise de textos, músicas, vídeos, contação de histórias, teatro, tecnologia, oficinas, grupos de estudos, entre outros recursos didáticos para abordar essas questões em sala de aula ou fora dela.

E para que essas ações sejam efetivas no ambiente escolar faz-se necessário que o docente esteja preparado, capaz de perceber as lacunas existentes, os preconceitos e estereótipos

Revista de Pesquisa Interdisciplinar, Cajazeiras, n. 2, suplementar, p. 29 - p. 37, set. de 2017. 
que marcam a escola e a sociedade. Professores capacitados se tornam aptos a discutir sobre questões de gênero de maneira acessível, utilizando exemplos, atividades lúdicas e conversas sinceras. Podemos encontrar esses conteúdos em desenhos animados, onde podem ser trabalhadas as questões sobre a equidade entre meninos e meninas.

O ideal é esquecer os longos textos cheios de termos acadêmicos e as discussões complexas sobre o que é gênero e o que é sexualidade - eles podem ter um papel importante na universidade e em outros ambientes educativos, mas, com crianças, as questões de gênero são muito mais simples.

Por isso, discutir gênero nas escolas é importante e urgente: afinal, o papel do ambiente escolar não é somente preparar os alunos para provas e vestibulares, mas também promover a cidadania e a responsabilidade social para professores, coordenadores, funcionários, alunos e suas famílias.

\section{REFERÊNCIAS BIBLIOGRÁFICAS}

CARVALHO, M. A construção das identidades no espaço escolar. Revista Reflexão e Ação, Santa Cruz do Sul, v.20, n.1, p.209-227, jan./jun.2012.

COSTA, F. O.; ANTONIAZZI, A. S. A influência da socialização primária na construção da identidade de gênero: percepções dos pais. Paidéia, Ribeirão Preto, p. 67- 75, 1999.

CUNHA, A.T. B da.; SANTOS, L. P. Homens na docência: novas masculinidades? In: Género y Sociedad: "vocês, cuerpos y derechosen disputa", 3, 2014, Córdoba - Angentina. Anais... Angentina: - UNC, 2014. Online.

JESUS, J. G de. Orientações sobre identidade de gênero: conceitos e termos. 2. ed. Brasília: EDA/FBN, 2012. 42p.

NEVES, L. M. B. et al. Tutorial de Pesquisa Bibliográfica. Pesquisa Científica, Paraná, p. 01$48,2013$.

PERETTI, C.; NATEL, A. Identidade de gênero: a vida em suas diferentes dimensões. JOINTH, Curitiba - PR, v.3, n.1, p. 170- 183, 2013. 
RIBEIRO, M. D. Gênero e diversidade sexual na escola: sua relevância como conteúdo estruturante no ensino médio. Ensino de Sociologia em Debate, Londrina, v. 1, n. 2, p. 01-21, jul./dez. 2012. 